\title{
Willingness to pay more for value-added pomegranate juice (Punica granatum L.): An open-ended contingent valuation
}

\author{
Karen Rodrigues Romano ${ }^{\mathrm{a}}$, Fernanda Dias Bartolomeu Abadio Finco ${ }^{\mathrm{b}}$, Amauri Rosenthal ${ }^{\mathrm{c}}$, \\ Marcus Vinicius Alves Finco ${ }^{\mathrm{d}}$, Rosires Deliza ${ }^{\mathrm{c}, *}$ \\ a Federal Rural University of Rio de Janeiro, Food Technology Department, Seropédica, RJ, Brazil \\ ${ }^{\mathrm{b}}$ Federal University of Rio de Janeiro, Institute of Biophysics Carlos Chagas Filho, Laboratory of Radioisótopos Eduardo Penna Franca, Rio de Janeiro, Brazil

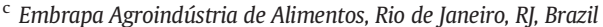 \\ d Ibmec, Rio de Janeiro, RJ, Brazil
}

\section{A R T I C L E I N F O}

\section{Article history:}

Received 19 April 2016

Received in revised form 18 August 2016

Accepted 26 August 2016

Available online 27 August 2016

\section{Keywords:}

Pomegranate juice

Willingness to pay

Contingent valuation method

Consumer.

\begin{abstract}
A B S T R A C T
This study aimed at estimating the consumer's willingness to pay (WTP) more for value-added pomegranate juice using the contingent valuation method (CVM). The WTP was estimated applying the open-ended elicitation technique with 454 consumers in two supermarkets located in Rio de Janeiro, Brazil. The average consumer's WTP more for pomegranate juice was estimated in $\mathrm{R} \$ 2.04$ (Brazilian currency) and the income elasticity coefficient at the midpoint was 0.19 , i.e., a $10 \%$ increase in consumer income will increase, on average, $1.9 \%$ the WTP of pomegranate juice (ceteris paribus). Therefore, the income elasticity coefficient was considered inelastic, once an increase in income would have low effect on the WTP for these consumers. The results indicated that the consumers were interested in acquiring a non-traditional juice processed using a technology that preserves vitamins and antioxidants, maintains the flavor of "fresh juice" without colorants and preservatives, despite the pomegranate is not part of the Brazilian diet.
\end{abstract}

(c) 2016 Elsevier Ltd. All rights reserved.

\section{Introduction}

Consumers are more aware of the beneficial impact of the eating habits on their health, growing the interest and the consumption of healthy products even processed foods. This consumer's attitude motivates food and beverage industries to deliver more nutritious and functional products in the market with sensory attributes appreciated by consumers (Kim \& Kwak, 2015; Andrés, Tenório, \& Villanueva, 2015). The beverage industry is considered the most active functional food category to aggregate convenience and nutritional value (Corbo, Bevilacqua, Petruzzi, Casanova, \& Sinigaglia, 2014). The sales of this product category are growing fast in Brazil, in spite of the economic crisis the country is facing (Mercado de sucos saudáveis cresce rápido mesmo durante a crise, 2016). The sales of natural items, with health appeal, skyrocketed in the past five years. According to the AgroServices (2015) the sales increased 98\% in 2015 compared to 67\% of the traditional ones. These figures place Brazil as the fourth largest consumer market for healthy products in the world. Several ready-todrink formulations have been developed, mainly using fruits and vegetables, aiming to preserve/improve the nutritional content.

\footnotetext{
* Corresponding author.

E-mail address: rosires.deliza@embrapa.br (R. Deliza).
}

Pomegranate is an ancient fruit rich in nutrients and health benefits consumed mainly in natura and as a juice (Tárrega et al., 2014). The fruit has bioactive phytochemicals that are beneficial to the health with antimicrobial, anti-inflammatory, and anti-carcinogenic actions; as well as the ability of helping preventing cardiovascular diseases (Beaulieu et al., 2015; Szychowski et al., 2015). Despite the pomegranate is well known worldwide, this fruit is not popular in Brazil, although it is frequently used in juicy blends or as an ingredient in formulated foods, but not as the main juice ingredient (Romano, Rosenthal, \& Deliza, 2015). This low popularity among Brazilians can be related to the low availability of the product in the market, and to the lack of consumer information about pomegranate health benefits, which, consequently, decreases the interest to purchase the fruit and pomegranate products, affecting also the fruit production system. However, many efforts have been done to enhance the production and establish the pomegranate and its derivatives (e.g. juice) in the food market. Its cultivation is part of a current agricultural public policy to boost the Brazilian semi-arid region (Freitas, Coelho, Maia, \& Azevedo, 2012; Costa \& Marinho, 2016). Therefore, the investigation of consumer attitude towards pomegranate juice carrying itself the claim of a functional and healthy food turns a relevant issue to the insertion and consolidation of pomegranate in the fruit juice market. Such investigation is aligned with the trend of adding healthiness and convenience to the product (Siró, Kálpolna, Kápolna, \& Lugasi, 2008; Barbosa, Madi, Toledo, \& Rego, 2010; Hernández-Carrión, 
Varela, Hernando, Fiszman, \& Quiles, 2015; Siegrist, Shi, Giusto, \& Hartmann, 2015). Indeed, the obtained data is important to elucidate the Brazilians attitude towards a novel product.

Moreover, it is known that a product choice involves several elements as consumer perception, expectations, social and psychological factors, financial contexts and intrinsic and extrinsic product features (Deliza \& MacFie, 1996; Fernqvist \& Ekelund, 2014; Gutjar, Graaf, Palascha, \& Jager, 2014, Hersleth, Monteleone, Segtnan, \& Naes, 2015). Price is characterized as an extrinsic feature determinant in intention to purchase (Ares, Giménez \& Deliza, 2010). Studies have been conducted to measure the consumer willingness to pay, aiming at investigating how price affects the consumer purchase. It consists of evaluating the monetary value the consumer assigns to goods or services they desire to acquire. Consequently, it also allows measuring the feasibility of the product in the market. However, the consumer willingness to pay for functional foods will depend of how she/he perceives them, and her/ his concerns towards health (Lawless, Drichoutis, R.M., Threlfall, \& Meullenet, 2015; Ares, Giménez \& Deliza, 2010).

Different methodologies have been employed aiming to evaluate the willingness to pay for products, among them, the Contingent Valuation Method (CVM), which is characterized by having a declared preference, and estimates economic values often utilized to measure goods and services (Mergenthaler, Weinberger, \& Qaim, 2009). The CVM has been used to measure the willingness to pay for maintenance/increment of the amount or quality of the environmental good or a product, or the willingness to accept (WTA) the compensation for the reported quality (Tisdell, Wilson, \& Nantha, 2008).

In market researches, this method can estimate values and increments in the quality of food products such as: apple enriched with antioxidant coatings (Zaikin, Andrey \& McCluskey, 2013), certified Atlantic farmed salmon (Haghiri, 2014), organic fresh milk (Huang \& Lee, 2014), cheese (Barnes, Bosworth, Bailey, \& Curtis, 2014), sensory attributes in beer (Gabrielyan, McCluskey, Marsh, \& Ross, 2014), and dried native chili (Garcia-Yi, 2014). This study aimed at estimating the consumer's willingness to pay (WTP) more for a value-added non-traditional juice processed using a technology that preserves vitamins and antioxidants, keeps the flavor of "fresh juice" without adding colorants and preservatives.

\section{Material and methods}

\subsection{Participants and data collection}

The survey was carried out in two supermarkets of Rio de Janeiro State, Brazil, i.e. it had an in-store setting. The supermarkets were located in areas with very different socioeconomic levels to allow the participation of consumers with distinct incomes. Five hundred individuals who consumed and purchased processed fruit juice, aged between 18 and 70 years old, of both genders were invited to take part in this study. They were approached in the supermarket, informed about the aim of the study, and invited to participate. When the person has accepted the invitation, the Consent Form was presented and signed. After this procedure, the interview started.

The data collection was carried out through a cross-sectional survey, which comprised of specific questionnaires specially developed to this study with closed, as well as open-ended questions (Gil, 1995). Questionnaires were applied by graduate students of the Federal Rural University of Rio de Janeiro, who were trained and were able to perform this task. It was divided in three parts. The first part collected socioeconomic data, and the second one the willingness to pay (more) for pomegranate juice. Before answering the willingness to pay (more) task, consumers were presented to the following hypothetical scenario "the pomegranate juice was processed by a technology that preserves vitamins and antioxidants (beneficial to the health), keeps the flavor of "fresh juice " and there was no addition of colorants and preservatives". Finally, the third part of the study evaluated the consumer attitude towards health, through the General Health Interest subscale (HTAS), and the food neophobia using scales developed by Pliner and Hobden (1992). The HTAS was translated and validated to Portuguese by Soares, Deliza \& Gonçalves (2006) and is composed of three subscales; however, this study used only the General Health Interest subscale. The data of HTAS subscale was analyzed together with the WTP to verify the relationship between the consumer willingness to pay more for pomegranate juice and his/her general health interest using ANOVA, and considering the WTP intervals and the consumers as source of variation, followed by the Kruskal Wallis test to check statistical differences between the WTP respondents.

The neophobia scales were translated and adapted from the English language to Portuguese. Thirty-two individuals who were fluent in English and Portuguese answered the questionnaire to verify the semantics comprehension. Some modifications were made, as the substitution of "ethnic foods" to "other cultures", to make easier the participant comprehension. Neophobia scores were categorized as follows: up to 25 - neophilic individuals; 26-44 - neutral individuals; 45 and higher - neophobic person (Olabi, Najm, Baghdadi, \& Morton, 2009). The food neophobia data were analyzed using ANOVA followed by the Kruskal Wallis test to look for significant differences among the WTP interviewees.

Before the data collection in the supermarkets, a pilot study was carried out at Embrapa Food Technology with 32 individuals with the goal of checking the ability of participants to understand the questions. These data were not used in the further statistical analyses.

\subsection{Methods}

Several methods can be applied aiming at assessing the willingness to pay, being remarkable the improvement in studies, as well as in the specific literature about economic evaluation. However, the choice of the right method or the most appropriate one depends, mainly, on a deep analysis of the real research objective, as well as the empiric experience of the researcher (Finco \& Abadio-Finco, 2010). Therefore, as the main objective of the study was the use value estimation (willingness to pay); the contingent valuation method (CVM) was chosen. Besides, there was an additional methodological interest in combining the contingent valuation method in a consumer science scenario, which is a novelty for the mentioned method.

\subsubsection{Willingness to pay estimation procedure}

Aiming at estimating the willingness to pay (WTP), the contingent valuation method (CVM) was applied since this method is appropriate to estimate economic values of goods and services that have no price directed revealed in the market (Tisdell, 1991). CVM creates a hypothetical marketplace in which no actual transactions are made. The method involves direct questions to consumers about their willingness to pay more for the improvement of benefits provided by any resource, and requires that the person inquired understands the scenario described, as well as the possible qualitative and quantitative variations, which might occur. It is mostly used to estimate economic values for all kinds of ecosystem and environmental services, and it has been successfully used for commodities that are not exchanged in regular markets, or when it is difficult to observe market transactions under the desired conditions. Many applications of the method deal with public goods such as improvements in water or air quality, amenities such as national parks, and private non-market commodities such as reductions in the risk of death, days of illness avoided or days spent hunting or fishing (FAO, 2016).

The CMV presents advantages as flexibility, being able to measure practically any good or service (Bateman, Langford, Turner, Willis, \& Garrod, 1995, Mergenthaler et al., 2009). In addition, it is a cheap methodology, easy to be applied via internet (Chen et al., 2013), SMS text (Shariful Islam et al., 2016) or using a face-to-face interview (GarciaYi, 2014). However, this methodology presents disadvantages, as the 
questionnaire needs to be well structured or it can generates bias, making it difficult to the interviewee to reveal her/his true willingness to pay (Carson, Flores, Martin, \& Wright, 1996). Venkatachalam (2004) addressed the validity and reliability as critical issues. Despite some criticism that emerges from the use of CVM, many researchers still recommend this method (Chen et al., 2013).

The open-ended elicitation technique was chosen to fit in the currently study considering three factors. Firstly, this technique is easy to be understood by consumers; the second issue refers to the fact that participants were directly asked about how much more he/she would be willing to pay, creating a continuous bids variable that estimates the mean WTP more (Venkatachalam, 2004). Finally, the quick data collection is considered the third factor, taking into account that consumers hardly like or even are able to spend long time in the supermarket if other elicitation techniques are applied, such as payment cards, bidding game, dichotomous choice, which require more time to be performed. Based on that, it was created a hypothetic scenario on pomegranate juice (described in Section 2.1), and doing so, the consumer was inquired about his/her maximum willingness to pay more for pomegranate juice. After the step described above, the WTP was estimated based on the Eq. (1) (Finco \& Abadio-Finco, 2010).

$W T P t=\sum_{i=1}^{y} W T P a(n i) / N$

where:WTPt $=$ total willingness to pay; $W T P a=$ mean value of willingness to pay; $n i=$ total of consumers willing to pay; $N=$ total of consumers inquired; $y=$ number of WTP intervals; $i=$ one of the WTP intervals:

The WTP figures were stratified in intervals that ranged from $R \$ 0.00$ (no willingness to pay) up to $\mathrm{R} \$ 5.00$ (or even more) per juice. An econometric model was formulated aiming at better understanding the relationship between the WTP and consumer's socioeconomic and behavioral indicators. The software STATA 12 was used to support the statistical and the econometric analysis.

\subsubsection{Variables definition and regression analysis}

Regarding the econometrics model, the dependent variable was specified and defined as the consumer's WTP according to Greene (2008) and Hill, Griffiths, and Lim (2008). On the other hand, socioeconomic indicators such as family income, gender, educational level, age, and the behavioral variables previous knowledge of pomegranate juice, and previous consumption of pomegranate juice were chosen as explanatory variables.

Based on that, the function of WTP for pomegranate juice can be expressed as showed in Eq. (2):

$W T P=f(I, A, E, G, P k, P C F F)$

where:WTP $=$ willingness to pay for pomegranate juice; $I=$ consumer's income per capita; $A=$ consumer's age; $E=$ consumer's educational level; $G=$ gender (dummy); $P k=$ previous knowledge of pomegranate juice by consumer (dummy);PC = previous consumption of pomegranate juice by consumer (dummy).

It is hypothesized that the signs of parameters are positive to consumer's income per capita, educational level, previous knowledge and previous consumption, and negative to consumer's age. A person with higher income, for instance, is expected to declare a higher willingness to pay more for pomegranate juice. Similarly, it is expected that consumers with higher educational level demonstrate more concern about the quality of the fruit since they are informed about the functional (antioxidant) capacity of pomegranate, and, therefore, she/he would be more willing to pay more for pomegranate juice. Taking into account the consumer's previous knowledge and previous consumption of pomegranate, one should expect that the willingness to pay increases vis-à-vis the consumption in the past, since the demand for quality is normally positively related to the experience and previous use (Ekins, 1994).

Regarding the age, it is expected that in the case of pomegranate juice, the older the person the lower the WTP, as the youngest pursue fashionable food habits. It is important to emphasize that the assumptions hitherto are based solely on pomegranate juice and should not be applied to any kind of juice. Regarding the gender variable, there is no previous assumption since the literature is not clear about the relationship between gender and the willingness to pay for food products.

Therefore, an econometric model was specified aiming at obtaining the parameters associated to the described variables, as well as the hypotheses previously formulated (Eq.(3)),

$Y_{j}=a_{i}+\sum_{i=1}^{3} \beta_{i} X_{i j}+\sum_{i=1}^{3} \delta_{i} Z_{i j}+\mu_{j} \quad(j=1, \ldots, n)$

where: $Y_{j}=$ willingness to pay of consumer $j$, in $\mathrm{R} \$$ per product; $X_{1 j}=$ income per capita of consumer $j$, in $\mathrm{R} \$$ per product; $X_{2 j}=$ age of consumer $j$, in years; $X_{3 j}=$ educational level of consumer $j$, in years of study; $Z_{1 j}=1$ if consumer $j$ is male; 0 if otherwise $; Z_{2 j}=1$ if previous knowledge of consumer $j$; 0 if otherwise $; Z_{3 j}=1$ if previous consumption of consumer $j ; 0$ if otherwise $; \mu_{j}=$ error terms; $\alpha_{i}, \beta_{i}, \delta_{i}=$ parameters of regression $(i=1, \ldots, 3)$

Due to the lack of an explicit functional form from the literature, as well as the exogenous variables that should be used in studies about the willingness to pay, the ordinary least squares method (OLS) was applied to estimate the coefficients of the equation and the semi-log functional form was selected, in which the dependent variable is measured in logs and independent variables in levels, once this functional form better express the relationship between the dependent and explanatory variables.

The dependent variable in equation below is the natural logarithm of willingness to pay. To examine how explanatory variables affect the WTP, one needs to take the exponential of both sides (dependent as independent variables), since the exponential function reflects the anti$\log$ of the natural logarithm (Eq.(4)):

$$
\begin{aligned}
& Y=\operatorname{Exp}[\ln (Y)]=\operatorname{Exp}\left[a_{i}+\sum \beta_{i} X_{i}+\sum \delta_{i} Z_{i}+\mu_{i}\right. \\
& Y=e^{\alpha_{i}} e \sum \beta_{i} x_{i j} e^{\sum \delta_{i} Z_{i}} \\
& Y=\mathrm{e}^{a_{\mathrm{i}}+\sum \beta_{\mathrm{i}} \mathrm{x}_{\mathrm{i}}+\sum \delta_{\mathrm{i}} \mathrm{z}_{\mathrm{i}}+\mathrm{u}_{\mathrm{i}}}
\end{aligned}
$$

The equation above was derived and the interpretation of the estimated coefficients is called semi-elasticity and is represented by Eq.(5):

$\frac{d(\ln y)}{d x}=\beta, \delta=\frac{d y / y}{d x}$

where $\delta$ is the coefficients of $Z$ variables considering the percentage of differences in the willingness to pay when $\delta$ is equal to one compared to $\delta$ equal to zero.

\section{Results and discussion}

\subsection{Descriptive statistics}

Forty-six out of the 500 participating consumers were excluded from subsequent statistical analyses because their data were incomplete. Table 1 includes the minimum and maximum values, means and standard deviations of the socioeconomic variables of the 454 consumers, whose data were valid and included in the analyses. Based on the statistical descriptive analysis, it has been found that the income per capita, for instance, presented a large variability, varying from a minimum of $\mathrm{R} \$ 114.00$ up to a maximum of $\mathrm{R} \$ 34,000.00$ per month. 
Table 1

Participants' socioeconomic characteristics $(n=454)$

\begin{tabular}{lllll}
\hline Variable & Minimum & Maximum & Mean & $\begin{array}{l}\text { Standard } \\
\text { deviation }\end{array}$ \\
\hline Income per capita $(\mathrm{R} \$)^{\mathrm{a}} /$ month & 114,00 & $34.000,00$ & $2.622,72$ & $3.104,89$ \\
Age & 18 & 70 & 37.59 & 14.22 \\
Educational level $^{\mathrm{b}}$ & 1 & 7 & 4.95 & 1.43 \\
Gender (female/male) $_{\text {Previous knowledge }}$ & 0 & 1 & 0.36 & 0.48 \\
Previous consumption & 0 & 1 & 0.92 & 0.26 \\
\hline
\end{tabular}

a Real: the Brazilian currency.

b 1- incomplete Fundamental school; 2- Fundamental school; 3- incomplete High school; 4- High school; 5- Incomplete under graduation; 6- Under graduation; 7Graduation.

Among the socioeconomic variables, income presented the highest variability, being the unique to present the coefficient of variation ( $\mathrm{CV}=$ standard deviation/mean) $>1$. Even if is not enough to express a complete and absolute poverty and inequality situation; this variable indicates the diversity in the socioeconomic profile among the interviewees. This result was expected considering the large diversity of consumers who go to the supermarkets where the data were collected.

The age of individuals varied from 18 to 70 years old, showing the participation of potential young as well as old consumers (mean 37.59 years) in the study. Bett, Peters, Nwankwo, and Bokelmann (2013) and Lee and Yoo (2011) through the dichotomous choice elicitation form reported average ages of 35.69 and 36.42, respectively. GarciaYi (2014) investigated the WTP for dehydrated pepper and reported the mean age of 39.56 years, i.e., similar to the reported in the present study. Education level was measured in scales varying from 1 to 7 , with mean of 4.95 and standard deviation of 1.43 , showing that on average the potential consumers had complete high school level. In relation to the other variables, the minimum and maximum values corresponded to 0 and 1 , where 0 indicated that individuals did not know/did not consume the pomegranate fruit before, and 1 indicated that individuals $\mathrm{knew} / \mathrm{had}$ tasted the pomegranate, ex ante this study. The results revealed relatively high means ( 0.92 and 0.80 , respectively), suggesting that most of participants have already had some contact with the fruit (knowledge or consumption). Considering participants gender, the mean 0.36 indicates that the majority of consumers were women as female $=0$ and male $=1$.

\subsection{Estimation of the willingness to pay (WTP) more for pomegranate juice}

Table 2 presents the aggregate value of WTP, i.e. the total willingness to pay more (WTPt) for the pomegranate juice per ranges of Real (the Brazilian currency). From the 454 participants in the study, one can notice that $18.5 \%$ of consumers did not show any willing to pay more for the pomegranate juice, what is a non-negligible figure, indeed. However, they were still taken into account in the analysis because even though they cannot be considered "WTP contributors", they are potential consumers. Roughly $27 \%$ of participants wanted to pay an amount that ranged from $\mathrm{R} \$ 0.10$ up to $\mathrm{R} \$ 1.00$ more than a regular

Table 2

Willingness to pay (WTP) more for the product per range of Real (R\$)

\begin{tabular}{llll}
\hline WTP $(\mathrm{R} \$)$ & WTP (mean) & Number of consumers $\left(\mathrm{n}_{\mathrm{i}}\right)$ & \% of consumers \\
\hline 0,00 & 0.00 & 84 & 18.5 \\
$0.10-1.00$ & 0.75 & 122 & \\
$1.01-2.00$ & 1.79 & 75 & 16.5 \\
$2.01-3.00$ & 2.86 & 59 & 13.0 \\
$3.01-4.00$ & 3.86 & 49 & 10.8 \\
$4.01-5.00$ & 4.93 & 51 & 11.2 \\
above 5.01 & 6.57 & 14 & 3.1 \\
TOTAL $(\mathrm{N})$ & & 454 & 100
\end{tabular}

a Real, the Brazilian currency. industrialized fruit juice, and just 3.1\% of consumers were willing to pay more than $\mathrm{R} \$ 5.01$ per product.

Therefore, based on the Eq. (1), the estimated mean value of WTP was $R \$ 2.04$ per product, i.e. the consumer would be willingness to pay $\mathrm{R} \$ 2.04$ above the market price considering similar products.

One should expect that the willingness to pay using value and estimated through the contingent valuation method may support stakeholders interested in improvement of food quality and diversification. However, one also should bear in mind that the values estimated for the willingness to pay might not be used as a parameter for increasing the product price. Those values reflect, a priori, that consumers are interested in spending an extra amount of money aiming at having access to a novel food.

Studies combining sensory analysis and willingness to pay estimated through CMV have been applied mainly in alcoholic beverages. Gabrielyan et al. (2014) investigated sensory characteristics and consumers' WTP for beer aiming to measure whether specific sensory attributes play a role in determining WTP through dichotomous choice (double-bounded elicitation technique). The results showed the mainly intrinsic attributes that had positive impact on consumers' WTP were flavor and hoppiness. Tozer, Galinato, Ross, Milles, and McClusckey (2015) carried out a study with 109 consumers evaluating the sensory characteristics through a blind test and willingness to pay for four types of craft cider using the CVM. Results revealed that sensory evaluation (overall liking, taste, and aroma), the participant age, and if she/he was a cider drinker, contributed positively to the WTP. However, it was observed that the WTP decreased when participant was a beer drinker. In addition, the chemical analyses showed that tannin level had a positive effect on WTP, but an increased in sweetness, lead to a decreasing on the consumer WTP.

It is suggested that further studies are conducted to detect possible changes in the willingness to pay, in the number of consumers willing to pay and the explanation given for unwillingness to pay in respect to pomegranate juice. These studies, when conducted in a systematic and continuous way, are important for understanding the selection process adopted by the consumer, and to guide policies aimed to improve the consumer's wellbeing.

The results of General Interest in Health (HTAS) and the WTP intervals can be visualized in Table 3 .

The general health interest (HTAS) related with the willingness to pay intervals were not significant $(p=0.39)$, i.e., the willingness to pay more for pomegranate juice was not related with the consumer interest in health. The Kruskal Wallis (non-parametric) also was applied $(p=0.11)$, confirming the hypothesis that the means were not statistically different considering the WTP intervals.

According to Roininen, Lähteenmaki \& Tuorila (1999) the larger the individual score, the greater his/her concern in relation to health. In the present study, consumers showed scores close to 40 , i.e., between (39.98 and 41.28), demonstrating that they were concerned about health. Previous studies reported that claims on antioxidants and nutrient preservation due to technological process showed positive effects on consumer's choice (Zaikin \& McCluskey, 2013; Romano et al., 2015).

Similar analysis was carried out on the neophobia data and the WTP intervals (Table 4 ). The ANOVA ( $p=0.46$ ) suggested that there were no differences between the neophobia scale and the distinct WTP intervals.

Table 3

Relationship between the General interest in health ${ }^{\mathrm{a}}$ and the WTP intervals.

\begin{tabular}{llllll}
\hline Intervals (R\$) & No. obs. & Minimum & Maximum & Mean & Standard deviation \\
\hline 0.00 & 98 & 13 & 56 & 41.19 & 9.86 \\
$0.01-1.00$ & 130 & 8 & 56 & 40.98 & 9.73 \\
$1.01-2.00$ & 83 & 10 & 56 & 40.19 & 9.72 \\
$2.01-3.00$ & 66 & 17 & 56 & 40.60 & 11.29 \\
$3.01-4.00$ & 50 & 12 & 56 & 39.98 & 11.17 \\
$4.01-5.00$ & 54 & 11 & 56 & 40.48 & 9.90 \\
Above of 5.01 & 14 & 8 & 55 & 41.28 & 12.27 \\
\hline
\end{tabular}

a Rated in scales ranging from 1 (strongly disagree) to 7 (strongly agree). 
Table 4

Neophobia ${ }^{a}$ scale in relation to WTP intervals.

\begin{tabular}{llllll}
\hline Interval WTP $(\mathrm{R} \$)$ & No. obs. & Minimum & Maximum & Mean & Standard deviation \\
\hline 0.00 & 98 & 15 & 67 & 39.19 & 11.33 \\
$0.01-1.00$ & 130 & 10 & 60 & 35.20 & 9.16 \\
$1.01-2.00$ & 83 & 17 & 65 & 34.68 & 10.11 \\
$2.01-3.00$ & 66 & 14 & 60 & 36.12 & 11.20 \\
$3.01-4.00$ & 50 & 17 & 70 & 36.10 & 11.12 \\
$4.01-5.00$ & 54 & 14 & 57 & 35.66 & 9.74 \\
Above 5.01 & 14 & 22 & 56 & 36.07 & 10.35 \\
\hline
\end{tabular}

${ }^{a}$ Rated in scales ranging from 1 (strongly disagree) to 7 (strongly agree).

The Kruskal Wallis test (non-parametric) was applied ( $p=0.98$ ), confirming the hypothesis the means were not statistically different considering the WTP interview.

According to Olabi et al. (2009) the individual neophobia degrees can be measured in three groups: neophilic (score between 1 and 25), neutral (score between 26 and 45) and neophobic (score above 45). The results presented in Table 5 indicated that individuals of the current study were classified as neutral, since the average scores ranged between 34.68 and 39.19; however, the difference among WTP intervals were not significant.

\subsection{Willingness to pay more and the investigated variables}

Some tests were carried out aiming at investigating the model assumptions such as the Breusch-Pagan/Cook-Weisberg as well as the White test to check the presence of heteroscedasticity and the Variance inflation factors (VIF) to check the presence of multi-colinearity. The tests showed negative results for heteroscedasticity and multi-colinearity. In addition, the RESET test (Regression Specification Error Test) was applied to check about omitted variables and, again, the results pointed out towards the acceptance of no omitted variables in the model. The hypothesis tests, identifying the coefficients that differ from zero, were made considering a significance level up to $10 \%(p \leq 0.10)$. The main results can be seen in Table 5 .

All independent variables had significant effect $(p \leq 0.10)$ on the willingness to pay more for pomegranate juice. The income had a positive sign that is aligned with the economic theory, i.e. the higher the income the higher the consumer willingness to pay more for the product. Solgaard and Yang (2011); VanTra, Moritaka, and Fukuda (2011) and Chen et al. (2013) reported similar results for the income coefficient in their willingness to pay studies. The age had a significant effect $(p<0.01)$. The negative sign of the regression coefficient was according to the hypothesis of the study, showing that younger people were willing to pay more for pomegranate juice. These results were similar to Bett et al. (2013) and Zaikin and McCluskey (2013).

Although the educational level was significant, the sign of the coefficient did not follow the study hypothesis, which assumed that individuals with higher education level would have more willingness to pay

Table 5

Regression results for semi-log functional form.

\begin{tabular}{lllll}
\hline & Coefficient & SE & $t$-test & $p$-Value \\
\hline Constant & 1.64481 & 0.25878 & 6.36 & $<0.00$ \\
Income per capita $\left(X_{1 j}\right)$ & 0.00004 & 0.00001 & 2.69 & $<0.00$ \\
Age $\left(X_{2 j}\right)$ & -0.01548 & 0.00354 & -4.37 & $<0.00$ \\
Educational level $\left(X_{3 j}\right)$ & -0.05829 & 0.03531 & -1.65 & 0.10 \\
Gender $\left(Z_{1 j}\right)$ & -0.24583 & 0.09430 & -2.61 & 0.01 \\
Previous knowledge $\left(Z_{2 j}\right)$ & -0.42264 & 0.19509 & -2.17 & 0.03 \\
Previous consumption $\left(Z_{3 j}\right)$ & 0.25022 & 0.13709 & 1.83 & 0.07 \\
Coefficient of determination $\left(\mathrm{R}^{2}\right)$ & 0.07 & & & \\
F statistic $(6.363)$ & 5.04 & & & $<0.00$ \\
ni & 370 & & & \\
\hline
\end{tabular}

$\mathrm{SE}=$ standard errors.

$\mathrm{ni}=$ total of consumers willing to pay (Eq. (1)). more for the product. Nevertheless, Sneed, Sharma, and Beattie (2005) and Hammit and Haninger (2007), for instance, did not find any specific relationship between education level and willingness to pay more for a product. On the other hand, some studies hypothesized and confirmed $(p<0.05)$ that higher interviewee education level implied in lower willingness to pay more for the product (Loureiro \& Umberger, 2003; Lee \& Yoo, 2011; Solgaard \& Yang, 2011; VanTra et al., 2011). Further studies should be carried out to help elucidating such as issue.

The dummy variable gender was significant and pointed out that women, on average, were more willing to pay more for the pomegranate juice than men. The elasticity in the mean point shows that woman is $6 \%$ more willing to pay than man.

The study considered the hypothesis that the consumer who knew/ heard about the pomegranate before (even if he/she has not tried the fruit or the juice) also would be more willing to pay more for the juice. However, one can observe that the consumer who have heard about pomegranate before demonstrated a willingness to pay $42 \%$ lower than those who did not know the pomegranate (ceteris paribus). One explanation for this result could be that previous information about the fruit including its nutritional value was not enough to make consumers pay more for the product. They would need to have an experience with the product, suggesting that the sensory properties played a role on their evaluation. On the other hand, consumers who already tried the pomegranate before showed a willingness to pay $25 \%$ higher compared with consumers who had never tasted the fruit before.

The coefficient of determination $\left(R^{2}\right)$ was low; however, this was expected since the data are cross-sectional, which provides us with a snapshot of that population at the same point of time. This fact is, at least in part, explained by the high variation of bids, i.e. the high variation of the willingness to pay declared by consumers through openended questions (Greene, 2008).

The elasticity in the mean point was also calculated and is 0.19 , i.e. an increase of $10 \%$ on the consumer income will lead to an increase of $1.9 \%$ in the willingness to pay more for pomegranate juice, ceteris paribus. The demand, however, can be considered inelastic since an increase in income has a small effect on willingness to pay more for the product.

\section{Conclusions}

In the current study, consumers were willing to pay $\mathrm{R} \$ 2.04$ above the price of a conventional fruit juice for the pomegranate juice processed by a technology that is able to preserve vitamins and antioxidant compounds, to keep the flavor of "fresh juice" without adding colorants and preservatives. This estimated value can be considered high, showing that consumers are willing to pay more for the juice; however, we do not have enough data to infer the magnitude of this estimation over other processed juices of traditional flavors in Brazil such as mango, passion fruit, orange, etc.

Despite pomegranate is considered a non-traditional tropical fruit, and has low consumption in the Brazilian diet, $81.5 \%$ of participants were willing to pay more for the pomegranate juice. It may suggest that consumers are interested in the preservation of freshness, nutrients and health benefits provided by the product described in the CMV scenario, overcoming the expectations and implying that pomegranate juice can be successful in the Brazilian market. The research confirmed the hypothesis that consumers with higher-income demonstrated higher willingness to pay more for pomegranate juice, suggesting that this unfamiliar juice may be more attractive to this specific consumer niche. One can suppose that there is still an opportunity for investments to be made in added-value products focusing on higher-income consumers, as they are less affected by the current economic situation. Therefore, marketing strategies should be focused on medium/high income consumers.

Taking into account methodological issues, it is worth emphasize that the study was carried out in-store setting, giving real-context to the data, and recruiting consumers with different income levels. On 
the other hand, a possible limitation of our study was the lack of an acceptance test, since it would contribute to better understanding how much participants would like the concept of functional food to develop a successful novel product (Verbeke, 2005).

\section{Acknowledgments}

The authors would like to thank the consumers who took part in the study. They also thank CAPES (Coordination for the Improvement of Higher Education Personnel) and FAPERJ (E 26/103.159/2011) (Foundation for Research Support of the State of Rio de Janeiro) for the financial support.

\section{References}

AgroServices (2015). Natural juices are gaining ground in Brazil. (Available at) https:// www.redeagroservices.com.br/en/Noticias/2015/08/Sucos-naturais-ganham-espacono-Brasil\#sthash.jUHY9oyl.dpuf

Andrés, V., Tenório, M. D., \& Villanueva, M. J. (2015). Sensory profile, soluble sugars, organic acids, and mineral content in milk- and soy-juice based beverages. Food Chemistry, 173, 1100-1106.

Ares, G., Giménez, A., \& Deliza, R. (2010). Influence of three non-sensory factors on consumerchoice of functional yogurts over regular ones. Food Quality and Preference, 21, 361-367.

Barbosa, L., Madi, L., Toledo, M.A., Rego, R.A. (2010). [The food trends]. In: Brazil food trends 2020. Madi, L., Costa, A.C.P.B. \& R.A. Rego (Coord.). (Available at) http:// www.ital.sp.gov.br/tecnolat/anais/tl230513/Arquivos/Brasil\%20Food\%20Trends\% 202020.pdf

Barnes, R. N., Bosworth, R. C., Bailey, D. V., \& Curtis, K. R. (2014). Connecting sensory quality characteristics and local designations to willingness to pay for cheese at the retail level. International Food and Agribusiness Management Review, 17(3), 115-138.

Bateman, I. J., Langford, I. H., Turner, R. K., Willis, K. G., \& Garrod, G. D. (1995). Elicitation and truncation effects in contingent valuation studies. Ecological Economics, 12, 161-179.

Beaulieu, J. C., Lloyd, S. W., Preece, J. E., Moersfelder, J. W., Stein-Chisholm, R. E., \& ObandoUlloa, J. M. (2015). Physicochemical properties and aroma volatile profiles in a diverse collection of California-grown pomegranate (Punica granatum, L.) germplasm. Food Chemistry, 354-364.

Bett, H. K., Peters, K. J., Nwankwo, U. M., \& Bokelmann, W. (2013). Estimating consumer preferences and willingness to pay for the under utilized indigenous chicken products. Food Policy, 41, 218-225.

Carson, R. T., Flores, N. E., Martin, K. M., \& Wright, J. L. (1996). Contingent valuation and revealed preference methodologies: Comparing the estimates for quasi-public goods. Land Economics, 72, 80-99.

Chen, T., Song, M., Nanseki, T., Takeuchi, S., Zhou, H., \& Li, D. (2013). Consumer willingness to pay for food safety in Shanghai China: A case study of gap-certified milk. Journal Faculty of Agriculture, Kyushu University, 58, 467-473.

Corbo, M. R., Bevilacqua, A., Petruzzi, L., Casanova, F. P., \& Sinigaglia, M. (2014). Functional beverages: The emerging side of functional foods commercial trends, research, and health implications. Comprehensive Reviews in Food Science and Food Safety, 13, 1192-1206.

Costa, J. C., \& Marinho, M. G. V. (2016). Etnobotânica de plantas medicinais em duas comunidades do município de Picuí, Paraíba, Brasil. Revista Brasileira de Plantas Medicinais, 18, 125-134.

Deliza, R., \& MacFie, H. J. H. (1996). The generation of sensory expectation by external cues and its effect on sensory perception and hedonic ratings: A review. Journal of Sensory Studies, 11, 103-128.

Ekins, P. (1994). The environmental sustainability of economic processes: A framework for analysis. In J. Bergh van den, \& J. Straaten van der (Eds.), Towards sustainable development: Concepts, methods and policy (pp. 25-55). Washington DC: Covelo.

FAO (2016). Introduction and general description of the method of contingent valuation. (Available at http://www.fao.org/docrep/003/x8955e/x8955e03.htm. Accessed on 20 July 2016).

Fernqvist, F., \& Ekelund, L. (2014). Credence and the effect on consumer liking of food - A review. Food Quality and Preference, 32, 340-353.

Finco, M. V. A., \& Abadio-Finco, F. D. B. (2010). The consumer willingness to pay for food services: An analysis of the popular restaurant program in northern Brazil. Teoria e Evidência Econômica, 16(35), 350-364.

Freitas, A. V. L., Coelho, M. F. B., Maia, S. S. S., \& Azevedo, R. A. B. (2012). Plantas medicinais: um estudo etnobotânico nos quintais do Sítio Cruz, São Miguel, Rio Grande do Norte, Brasil. Revista Brasileira de Biociências, 10, 48-59.

Gabrielyan, G., McCluskey, J. J., Marsh, T. L., \& Ross, C. F. (2014). Willingness to pay for sensory attributes in beer. Agricultural and Resource Economics Review, 125-139.

Garcia-Yi, J. (2014). Identification of dried native chili markets in the international tourism sector in Peru: An open-ended contingent valuation study. Sustainability, 6, 1093-1106.

Gil, A. C. (1995). Métodos e Técnicas de Pesquisa Social. São Paulo: Editora Atlas S. A (207p).

Greene, W. H. (2008). Econometric analysis (Sixth edition ). Upper Saddle River: New Jersey, Prentice-Hall, New York University (1178p).

Gutjar, S., Graaf, C., Palascha, A., \& Jager, G. (2014). Food choice: The battle between package, taste and consumption situation. Appetite, 80, 109-113.
Haghiri, M. (2014). An evaluation of consumers' preferences for certified farmed Atlantic salmon. British Food Journal, 116(7), 1092-1105.

Hammit, J., \& Haninger, K. (2007). Willingness to pay for food safety: Sensitivity to duration and severity of illness. American Journal of Agricultural Economics, 89, 1170-1175.

Hernández-Carrión, M., Varela, P., Hernando, I., Fiszman, S. M., \& Quiles, A. (2015). Persimmon milkshakes with enhanced functionality: Understanding consumers' perception of the concept and sensory experience of a functional food. LWT - Food Science and Technology, 62, 384-392.

Hersleth, M., Monteleone, E., Segtnan, A., \& Naes, T. (2015). Effects of evoked meal contexts on consumers' responses to intrinsic and extrinsic product attributes in drycured ham. Food Quality and Preference, 40, 191-198.

Hill, R. C., Griffiths, W. E., \& Lim, G. C. (2008). Principles of econometrics (3rd edition ). Hoboken, NJ: John Wiley and Sons, Inc Available at http://principlesofeconometrics. com/poe3/poe3.htm

Huang, C., \& Lee, C. (2014). Consumer willingness to pay for organic fresh milk in Taiwan. China Agricultural Economic Review, 6(2), 198-211.

Kim, M. K., \& Kwak, H. S. (2015). Influence of functional information on consumer liking and consumer perception related to health claims for blueberry functional beverages. International Journal of Food Science and Technology, 50, 70-76.

Lawless, L. J. R., Drichoutis, A. C., Nayga, R. M., Jr., Threlfall, R. T., \& Meullenet, J. -F. (2015). Identifying product attributes and consumer attitudes that impact willingness-to-pay for a nutraceutical-rich juice product. Journal of Sensory Studies, 30(2), 156-168.

Lee, J. S., \& Yoo, S. H. (2011). Willingness to pay for GMO labeling policies: The case of Korea. Journal of Food Safety, 31, 160-168.

Loureiro, M. L., \& Umberger, W. J. (2003). Estimating consumer willingness to pay for country-of-origin labeling. Journal of Agricultural and Resource Economics, 28, 287-301.

Mercado de sucos saudáveis cresce rápido mesmo durante a crise (2016r). (Available at) http://g1.globo.com/globo-news/mundo-sa/videos/v/mundo-sa-mercado-de-sucossaudaveis-cresce-rapido-mesmo-durante-a-crise/4934634/

Mergenthaler, M., Weinberger, K., \& Qaim, M. (2009). Consumer valuation of food quality and food safety attributes in Vietnam. Review of Agricultural Economics, 31(2), 266-283.

Olabi, A., Najm, N. E. O., Baghdadi, O. K., \& Morton, J. M. (2009). Food neophobia levels of Lebanese and American college students. Food Quality and Preference, 20, 353-362.

Pliner, P., \& Hobden, K. (1992). Development of a scale to measure the trait of food neophobia in humans. Appetite, 19, 105-120.

Roininen, K., Lähteenmaki, L., \& Tuorila, H. (1999). Quantification of Consumer Attitudes to Health and Hedonic Characteristics of Foods. Appetite, 33, 71-88.

Romano, K. R., Rosenthal, A., \& Deliza, R. (2015). How do Brazilian consumers perceive a non-traditional and innovative fruit juice? An approach looking at the packaging. Food Research International, 74, 123-130.

Shariful Islam, S. M., Lechner, A., Ferrari, U., Seissler, J., Holle, R., \& Niessen, L. W. (2016). Mobile phone use and willingness to pay for SMS for diabetes in Bangladesh Journal of Public Health, 38(1), 163-169.

Siegrist, M., Shi, J., Giusto, A., \& Hartmann, C. (2015). Worlds apart. Consumer acceptance of functional foods and beverages in Germany and China. Appetite, 92, 87-93.

Siró, I., Kálpolna, E., Kápolna, B., \& Lugasi, A. (2008). Functional food. Product development, marketing and consumer acceptance - a review. Appetite, 51, 456-467.

Sneed, C., Sharma, A., \& Beattie, S. (2005). Restaurant consumers' concern for food safety and their willingness to pay extra for food safety. Institute for Food Safety and Security. Iowa State University (Available at) http://www.fsis.usda.gov/wps/wcm/connect/475e290f-97ea-43dcb255-bd9620f1feb4/Slides_092806_JSneed1.pdf?MOD=AJPERES\&amp\%3BCACHEID = de5104f2-43f9-46ea-911f-665a31a36305

Soares, L. L. S., Deliza, R., \& Gonçalves, E. B. (2006). Escalas atitudinais utilizadas em estudos de consumidor: Tradução e validação para a língua portuguesa. Alimentos e Nutrição. 17, 51-64 Available in: http://200.145.71.150/seer/index.php/alimentos/ article/view/211/213.

Solgaard, H. S., \& Yang. Y. (2011). Consumers' perception of farmed fish and willingness to pay for fish welfare. British Food Journal, 113, 997-1010.

Szychowski, P. J., Frutos, M. J., Burló, F., Pérez-López, A. J., Carbonell-Barrachina, A. A., \& Hernández, F. (2015). Instrumental and sensory texture attributes of pomegranate arils and seeds as affected by cultivar. LWT - Food Science and Technology, 60, 656-663.

Tárrega, M. A., Varela, P., Fromentin, E., Feuillère, Issaly, N., Roller, M., ... Fizman, S. (2014) Specific phenolic compounds and sensory properties of a new dealcoholized red wine with pomegranate (Punica granatum, L.) extract. Food Science and Technology International, 20(6), 421-429.

Tisdell, C. A. (1991). Economics of Environmental Conservation. Departament of Economics/University of Queensland. Australia: Elsevier.

Tisdell, C., Wilson, C., \& Nantha, H. S. (2008). Contingent valuation as a dynamic process. The Journal of Socio-Economics, 37, 1443-1458.

Tozer, P. R., Galinato, S. P., Ross, C. F., Milles, C. A., \& McCluskey, J. J. (2015). Sensory analysis and willingness to pay for craft cider. Journal of Wine Economics, 3, 314-328.

VanTra, P., Moritaka, M., \& Fukuda, S. (2011). Factors affecting Consumers' willingness to pay for functional foods in Vietnam. Journal of the Faculty of Agriculture, Kyushu University, 56, 425-429.

Venkatachalam, L. (2004). The contingent valuation method: a review. Environmental Impact Assessment Review, 24, 89-124.

Verbeke, W. (2005). Agriculture and the food industry in the information age. European Review of Agricultural Economics, 32, 347-368.

Zaikin, A. A., \& McCluskey, J. J. (2013). Consumer preferences for new technology: Apples enriched with antioxidant coatings in Uzbekistan. Agricultural Economics, 44 513-552. 